\title{
A new 16-membered tetraene macrolide JBIR-100 from a newly identified Streptomyces species
}

\author{
Jun-ya Ueda, Junko Hashimoto, Hideki Yamamura, Masayuki Hayakawa, Motoki Takagi and \\ Kazuo Shin-ya
}

The Journal of Antibiotics (2011) 64, 399; doi:10.1038/ja.2011.20; published online 6 April 2011

Addition to: The Journal of Antibiotics (2010) 63, 627-629; doi:10.1038/ja.2010.104

\begin{abstract}
T has come to the Editors' attention that the reportedly novel 1 bafilomycin analog 'JBIR100' published in The Journal of Antibiotics, October issue, 63, 627-629 (2010), is identical to TS155-2 in structure. TS155-2 was reported as an inhibitor of the thrombininduced calcium influx in Japanese Unexamined Patent Application Publication No. P2000-302782A, ${ }^{1}$ and also as a secondary metabolite of Streptomyces sp. bl 47/4455 in Mahmoud. ${ }^{2}$ As the spectral data suggest that the planar structures of JBIR100 and TS155-2 are identical, the Editors wish to report this replication as a service to the readership. However, it should be noted that the stereochemistry of 12 asymmetric carbons of TS155-2 and JBIR100 has not been determined. In addition, we believe that the cytotoxic and V-ATPase
\end{abstract}

inhibitory activities of JBIR100 reported in The Journal of Antibiotics are useful for readers. The Journal apologizes to the readership for the incompleteness of the structure search during the review process.

1 Chikanishi, T., Koike, Y., Washimi, Y., Takeuchi, T. \& Koike, Y. TS155-2 and its manufacturing method. Japanese Unexamined Patent Application Publication No. P2000-302782A (2000).

2 Mahmoud, K. A. S. Nafisamycin, Cyclisation Product of a New Enediyne Precursor, Highly Cytotoxic Mansouramycins, Karamomycins Possessing a Novel Heterocyclic Skeleton and Further Unusual Secondary Metabolites from Terrestrial and Marine Bacteria. PhD thesis, Univ. Göttingen, http://webdoc.sub.gwdg.de/diss/2009/ mahmoud/mahmoud.pdf (2008). 